\title{
Reliability Assessment of Uninterruptible Power Supply (UPS) System for Medical Operations in Zaria Kaduna State
}

\author{
Akinsanmi Olaitan \\ Federal University Oye-Ekiti \\ Department of Electrical \\ \&Electronics Engineering
}

\author{
Adedayo Kayode \\ Babarinde \\ Federal University Oye-Ekiti \\ Department of Electrical \& \\ Electronics Engineering
}

\author{
Gerald Kelechi ljemaru \\ Federal University Oye-Ekiti \\ Department of Electrical \& \\ Electronics Engineering
}

\begin{abstract}
The paper presents the reliability assessment of Uninterruptible Power Supply (UPS) systems for medical operations in Zaria. The part stress method was used to assess the reliability. Data on the failure of an APC BK650MI UPS model were used as a case study. Special consideration was given to factors like environment, quality of utility and service personnel, and the results showed that there is a relatively low reliability of the system, for medical operations in Zaria than the country for which the system was designed (USA).
\end{abstract}

\section{General Terms}

Uninterruptible Power Supply, Reliability of UPS Systems.

\section{Keywords}

Reliability, Failure rate, Availability, Maintainability

\section{INTRODUCTION}

In medical centers such as Hospitals, Medical personnel are much concerned about the safety of the lives of their patients who are under medical operations such as surgery, emergency, treatment, etc. and as such Uninterruptible Power Supply (UPS) systems are always connected to the medical equipment to prevent the effect of power failure during such operations. The reliability of this system, which has an original environment for which it was designed for, becomes necessary to determine the degree to which it could be relied upon for medical operations in Zaria.

\section{RELIABILITY}

Reliability is defined as the "probability that an item would perform required function under given conditions for a stated period of time, usually 1000 or 1 million hours. This requires the understanding of probability and statistical concept, and has, therefore, been found to be a very important tool in forecasting the pattern of failure for systems and hence, the reliability assessment of the system at hand" (Akinsanmi 2013).

\subsection{Part Stress Method}

This is one of the two methods used in assessing the reliability of electronic equipment. In the Part Stress Method, the effect of various stress on the hardware are put into consideration; along side with the environmental factor and the quality of the utility whereas, the Part Count Method of assessing the reliability of systems is based on the number of different parts, quality level and application environment. The objectives in both cases is to determine the failure for a given system operating in a specific environment (Akinsanmi,
2007). However, the Part Stress Method is the better method for assessing the reliability of an existing system, based on the possibilities of considering various stresses peculiar to the equipment in a specific area of application, and as such could be relied upon to assess the reliability of the Uninterruptible Power Supply (UPS) systems for medical operations in Zaria.

\section{UNINTERRUPTIBLE POWER SUPPLY (UPS) SYSTEM}

A UPS is a system which is designed to provide a short term power supply to power demanding electronic equipment like computer, telecommunication equipment, operating (surgical) theatre lamps and so on.

The UPS filters out small utility line fluctuations and isolates equipment from large disturbances by internally disconnecting from the utility line while supplying power from its internal batteries until the line returns to safe values. The UPS continues to supply power to the connected equipment as long as the utility power does not return, until the battery is exhausted. It lends its use in computer applications, as standby power supply for telecommunication equipment, operating (surgical) theatres lamps; research centers lamps and so on. It is connected between a critical load and the mains power supply, to provide a well-regulated power supply under all rated load and input supply conditions. The system provides the following advantages:

Increased power quality- the UPS system contains controlled voltage and frequency regulator circuits that maintain its output within close tolerance at all times, irrespective of voltage or frequency variations on the input mains supply.

Increased Noise Rejection -By rectifying the input mains AC power to $\mathrm{DC}$, and then converting it back to AC, (ON-LINE), the design prevents any electrical noise present on mains supply from appearing as its output, therefore, your critical loads receive filtered power.

Power Blackout Protection -During periods of mains power failure, the UPS system continues to supply the load from its battery sources leaving the load immune from mains disturbances, even during a complete mains power blackout.

UPS is basically divided into two major types, namely ONline and OFF-line UPS. The ONLINE UPS is the type in which the inverter circuit is constantly engaged i.e. whether the supply is from the mains or the battery, whereas, the OFFLINE UPS is the type in which the inverter circuit is only engaged during the outage of the mains power supply 
(Akinsanmi, 2004).

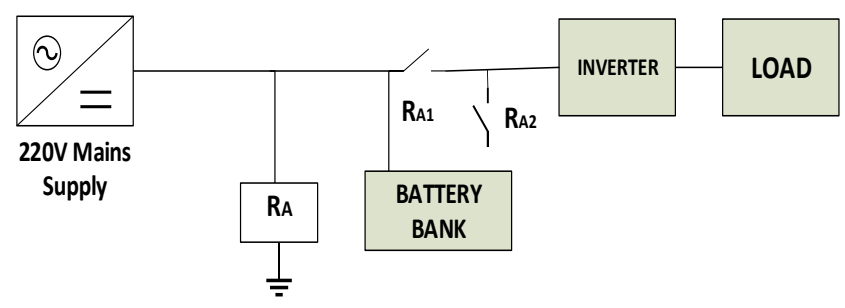

Figure 1: On-Line UPS

In Figure 1 above, the input supply from $\mathrm{PHCN}$ is rectified from $A C$ to $D C$. When relay $R_{A}$ is engaged, relays $R_{A 1}$ and $R_{A 2}$ are open. When relay $R_{A}$ is not engaged, relay $R_{A 1}$ is closed while $R_{A 2}$ is open, current flows into the inverter circuit and then to the load and the battery bank supply bank is being charged, but when the relay $\mathrm{R}_{\mathrm{A} 2}$ is closed, $\mathrm{R}_{\mathrm{A} 1}$ is open (when the mains supply fails) and the battery starts to feed the inverter and then to the load. This is the ON-LINE UPS mode of operation.

In Figure 2, when the relay $R_{A}$ is engaged, the relay $R_{A 1}$ and $R_{A 2}$ are closed. When relay $R_{A 1}$ is closed, $R_{A 2}$ is open, there is a supply voltage to the load without the in inverter circuit. The battery bank is charged at the same time, but the relay $R_{A 2}$ is closed, $R_{\mathrm{A} 1}$ is open and the inverter circuit receives supply and then to the load. This is the OFF-LINE UPS mode of operation (Akinsanmi,2004).

Of the two types, the on-line UPS is the predominant type in the market because of the following advantages:

Provision of continuous quality power

Protection of load from sudden power troubles that is associated with the mains power supply.

Provision of increased efficiency

\subsection{The Feature of a UPS}

A UPS is made up of two basic sub units, namely, the charger and the inverter units.

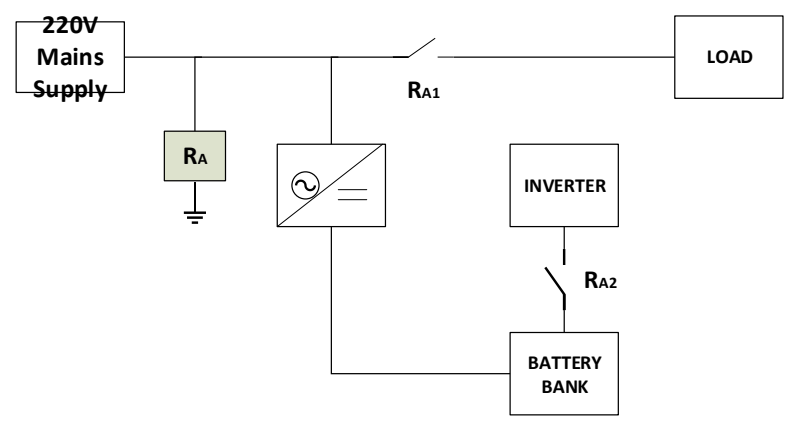

Fig 2: Off-Line UPS

\subsection{The Charger Unit}

This is the unit which is designed to produce a well regulated voltage for charging the battery bank of the UPS. It is made up of the power supply and the automatic overload protecting device part.

The power supply unit is made up of a step down transformer which steps down the $240 \mathrm{Vac}$ to $12 \mathrm{Vac}$, the rectifier which is generally the bridge type is used to convert the $12 \mathrm{Vac}$ to $12 \mathrm{Vdc}$. This bridge rectifier has the advantage of not using a centre tap transformer and suitability for high voltage application. The rectified voltage is then filtered by a filter circuit which could be a capacitor, inductor or combination of the two or resistor-capacitor filter. The filtered dc voltage is then regulated with the help of a voltage regulator which could be a zener diode voltage regulator integrated circuit chip. The $12 \mathrm{Vdc}$ serves to charge the battery bank.

The automatic overload protection device protects the battery from being overcharged (Akinsanmi, 2004).

\subsection{The Inverter Unit}

This is the unit which converts the $12 \mathrm{Vdc}$ provided by the battery to $12 \mathrm{Vac}$ through inversion process and further steps it up to $230 \mathrm{Vac}$ for load consumption. Inversion process could be through thyristor, MOSFET (metal-oxide semiconductor field effect transistor) or Bi-polar junction transistor (BJT). The MOSFET type "is the most commonly used type in commercial UPS because of the advantage of being a voltage device as against the BJT which is a current device, and can easily be turned on and off, with the control circuitry being less complex and hence, cheaper' (Akinsanmi, 2004).

\section{DEVELOPING COUNTRIES}

Anyone who writes about developing countries is faced with inherent difficulties. The most persistent of these is that doubts occur as to the possibility of generalizing about millions of people whose lives have one common element the pattern called under development from the point of view of technological advancement. These nations are mainly lands with tropical climates in Africa, Asia and Latin America. This work will be directed to Nigeria (a developing country) with specific emphasis on Zaria.

\subsection{Zaria (Kaduna State)}

Zaria is a major town in Kaduna State that has a critical combination of temperature, condensation, high relative humidity, and contaminants in the atmosphere such as salt, fungus, sand and dust. These have been known to cause' catastrophic failures in equipment, or in many cases, gradual deterioration of materials and surfaces so that service life is prematurely shortened. The area is periodically subjected to a very dry dust-laden atmosphere (harmattan) which rises from the Sahara Desert and is carried by winds from that area. This dust laden wind has been known to be charged and measurement shows that field strengths or, above $4000 \mathrm{~V} / \mathrm{m}$ can be reached during typical harmattan period. Metallic objects moving in this environment accumulate an average of $1000 \mathrm{~V} / \mathrm{m}$ charge and human contact with them produces perceivable electric shock. Temperatures in the sub-region range from $10^{\circ} \mathrm{C}$ to $40^{\circ} \mathrm{C}$ through the year and relative humidity vary from close to $100 \%$ along the sea coast to only a few percent in the North.

Another significant factor that must be taken into consideration is the presence of voltage fluctuations and transient disturbances in the distribution network of the electric supply. These could create serious operational problems for sensitive medical equipment like the UPS systems (Taylor, 1989).

\subsection{Reliability Indices}

It is convenient to specify the reliability of electronic equipment by some probability parameter, which give indication of the failure rate of such a system or equipment and does not depend on the operating time. By using such 
parameters, it is also possible to compare the performance between different systems with different operating periods. Two of such parameters that are commonly used are the mean time before failure (MTBF) and mean time to failure (MTTF).

\section{MEAN TIME BEFORE FAILURE (MTBF)}

System users are usually concerned with the length of time that a system will run without failure. This is the measure of the reliability of such system. For a repairable system, the time before failure is the critical measure, while for nonrepairable systems, the time distribution is exponentially decreasing and the mean time before failure (MTBF) is the mean or average time before successful failure of the system. The MTBF can be obtained by running a system for a predetermined length of time under specified conditions. Calculating the average length of time before failures could be seen as exponentially decreasing function and MTBF is the mean time before consecutive failures. Hence for the failure rate $\lambda$ is the number of failures per unit time, MTBF is given as

$$
M T B F=\frac{1}{\lambda}
$$

For a probability of survival $P \mathrm{t}$ and for a constant failure rate $\lambda$, the reliability $\mathrm{R}$ is given as

$$
R=P t=e^{-\lambda t}
$$

Where $P \mathrm{t}=\mathrm{R}$ is the reliability of the system and $\mathrm{t}$ is the specified period of failure free operation and then

$$
\lambda=\frac{1}{M T B F}=\text { Failure rate }
$$

\section{1 . Mean Time to Failure (MTTF)}

The mean time to failure MTTF is used for components or items that are not repairable e.g. filament bulbs, resistors, capacitors and so on, which are disposed as soon as they fail. This MTTF 'can be obtained by stressing a large number of components under known conditions for a period of time and noting the number of failures"' (Akinsanmi,2013).

\subsection{Equipment Failure Profile}

Over the years, complex equipment and components have been found to follow a familiar pattern or failure, which has been well documented. Hazard or failure rates have been calculated for equal time interval from installation to replacement. When the failure rate is plotted against a time scale spanning the equipment life time, the resulting graphics, popularly known as 'bathtub' is obtained as shown in Figure 3.

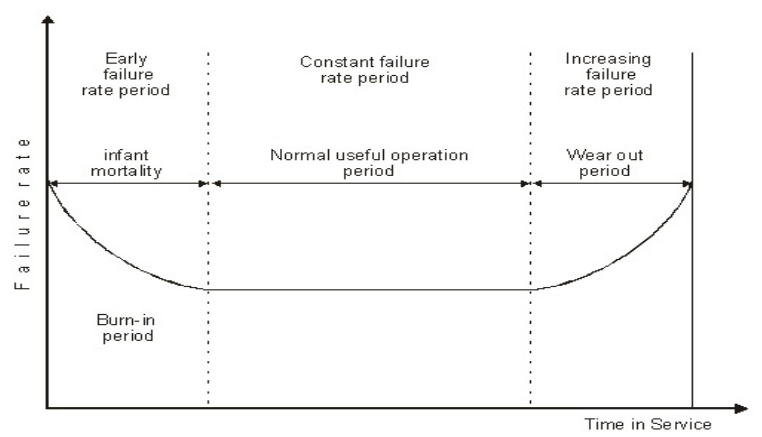

Figure 3 :Equipment Failure Profile Bathtub Curve
It exhibits three distinct periods or zones- the infant mortality period, the constant failure rate period and the wear out period. Failure rate is usually expressed in failure per hour (or failure per thousand or even per million hours) (Andrew et al, 1995).

\subsection{Infant Mortality Period}

This is the running-in period. During this period, the failure rate has been found to be high due to other design or manufacturing errors, misuse or misapplication of other identifiable causes. It however falls off rapidly with operation. Failures in this period can be avoided during product development through the use of stimulated tests, or by vigorous stressing during commissioning tests.

\subsection{Constant Failure Rate Period}

This period follows the running-in period. During this period, the failure rate is lowest and is a function of the basic design. Failure results either through accidents or poor operation or maintenance and they can be reduced by good control of operating and maintenance procedures. In this phase, the mean time to failure (MTTF) is the reciprocal of the (constant) failure rate (Akinsanmi 2009).

\section{5 . Wear Out Period}

This period manifests towards the tail end or the equipment component life. During this period, failure is due to old age; various components are worn out, metals become embrittled, insulation dries out and so on. Failure rates can only be reduced by preventive replacement of these components.

Generally, in some systems, one or two of the phases (usually the early failures and wear out failures) could be more reduced or effectively absent. Therefore, estimates for the parameters that affect the equipment failure profile of the constituent components, especially the length of the constant failure rate period and the associated failure rates are essential ingredients for predicting the reliability (Akinsanmi, 2004).

\subsection{Equipment Availability}

Equipment availability is the probability that an equipment will perform its required function at a stated instant of time or over a stated period of time. Availability is function of the utilization factor (U). The utilization factor of a unit or system is defined as the ratio of the operating time $\left(t_{o p}\right)$ to the sum of the maintenance time $t_{m}$, idle time $\left(t_{i d}\right)$ which may occur between completion of maintenance and use due to administrative reasons, and the operating time, Mathematically, the utilization factor U, can be expressed as

$$
U=\frac{t_{o p}}{t_{m}+t_{i d}+t_{o p}}
$$

If the idle time is equal to zero and the maintenance time becomes as small as possible, then utilization factor will approach its maximum value and can now be called availability of a unit or system, Mathematically, this can be expressed as

$$
A=U_{\max }=\frac{t_{o p}}{t_{m}+t_{o p(\min )}}
$$


However, the mean time between failure $(\mathrm{MTBF})=t_{o p}$ and the mean time to failure (MTTF) $=t_{m(\min )}$,then

$$
A=\frac{M T B F}{M T B F+M T T F}
$$

Therefore, if the availability of equipment is given as 0.9 , it means that the equipment is working satisfactorily for $90 \%$ of the time, and under repair for the remaining $10 \%$.

\section{RELIABILITY ASSESSMENT OF ELECTRONIC EQUIPMENT}

The general expression for the failure rate of the parts stress method of assessing reliability is given as

$$
\lambda_{i}=\lambda_{B} \pi_{\varepsilon} \pi_{A} \pi_{Q} \pi_{N} \ldots / 10^{6} \mathrm{hrs}
$$

Where

$\lambda_{i}=$ the failure of the $\mathrm{i}^{\text {th }}$ part

$\lambda_{B}=$ Base failure rate obtained from

the derated data for each generic

part against normaized stress and

temperature factors

$\pi_{\varepsilon}=$ accounts for the environmental factors other than temperaturre

$\pi_{A}=$ account for secondary stresses (e.g.vibrations, shock,e.t.c)

$\pi_{Q}=$ accounts for the degree of manufacturing control

$\pi_{N}=$ accounts for any additional factor that has not been taken care of above

$\mathrm{n}=$ number of particular component

For the scope of this work, the above expression for the part stress method was reduced to the expression below based on the factors which described the environment under consideration.

$$
\begin{aligned}
& \lambda_{i}=n \lambda_{B} T K \\
& \text { where } \\
& \lambda_{i}=\text { the failure of the } \mathrm{i}^{\text {th }} \text { part } \\
& \mathrm{n}=\text { number of particular component } \\
& \lambda_{B}=\text { Base failure rate obtained from } \\
& \text { the derated data for each generic } \\
& \quad \text { part against normaized stress and } \\
& \text { temperature factors } \\
& \mathrm{T}=\text { room temperature of the environment } \\
& \mathrm{K}=\text { voltage stress ratio }
\end{aligned}
$$

The information to compute equipment failure rates using the above equation is as given by Taylor (1989) and Arsenault (1980), if the entire equipment is being used in a particular environment. The failure rates of the region under consideration (Zaria and the designed country) are summed up to calculate the inherent system reliability. These failures are constant and are best described by the exponential distribution law for the useful operating region, the reliability of

equipment or device can be given as

$$
R_{B}(t)=e^{-\lambda e_{f f} t}
$$

where $\lambda_{B}$ is the base failure rate. This expression can be modified to account for change in failure rates due to wide variation or operating voltages and high surge frequencies, so that the real reliability can be expressed as:

$$
R(t)=e^{-\lambda e_{f f} t}
$$

\subsection{Reliability Assessment of BK650MI

\begin{tabular}{|c|c|c|c|c|c|c|c|c|c|}
\hline $\begin{array}{l}\text { Circuir. } \\
\text { Ref }\end{array}$ & Description Part & Qty & $\mathrm{T}\left({ }^{\circ} \mathrm{C}\right)$ & & $\lambda_{\mathrm{BD}}\left(10^{-6}\right)$ & $\lambda_{\mathrm{BN}}\left(10^{-6}\right)$ & $V_{\text {stress }}$ & $\lambda_{\text {BDeff }}$ & $\lambda_{\text {BZeffss }}$ \\
\hline & & & (D) $21\left({ }^{\circ} \mathrm{C}\right)$ & $(\mathrm{Z}) 27\left({ }^{\circ} \mathrm{C}\right)$ & & & & & \\
\hline $\mathrm{F}_{3}$ & AC Fuse $(1 \mathrm{~A}, 230 \mathrm{~V})$ & 1 & 21 & 27 & 0.02 & 0.02 & 0.94 & $3.95 \mathrm{E}-07$ & $5.08 \mathrm{E}-07$ \\
\hline$F_{2}$ & $1 \mathrm{~A}, 125 \mathrm{~V}$ & 1 & 21 & 27 & 0.02 & 0.02 & 0.96 & 4.03E-07 & $5.18 \mathrm{E}-07$ \\
\hline$F_{1}$ & $30 \mathrm{~A}, 32 \mathrm{~V}$ & 1 & 21 & 27 & 0.02 & 0.02 & 0.375 & $1.58 \mathrm{E}-07$ & 2.03E-07 \\
\hline $\mathrm{F}_{4}$ & $30 \mathrm{~A}, 32 \mathrm{~V}$ & 1 & 21 & 27 & 0.02 & 0.02 & 0.375 & $1.58 \mathrm{E}-07$ & 2.03E-07 \\
\hline$I_{1}$ & LM78DN(Regulators & 1 & 21 & 27 & 0.007 & 0.91 & 0.125 & $1.84 \mathrm{E}-08$ & 3.07E-06 \\
\hline$I_{3}$ & CD40106BCN & 4 & 21 & 27 & 0.01 & 0.12 & 0.81 & $6.80 \mathrm{E}-07$ & $1.05 \mathrm{E}-05$ \\
\hline
\end{tabular} APC UPS}

The design criteria presented above will be used to assess BK650MI model of an APC UPS in Zaria and in the country for which it was designed for using a spreadsheet computer package (Microsoft Excel). Hence, there exist the designed failure rate, as it will be applicable to the system operating in the Zaria environment. The conclusions arrived at will be used to assess the reliability of the UPS in the two environments. The components of BK650MI APC UPS, with the generic failure rate which has taken care of the environmental factors and the application stress factor, and the results of the failure rates are as shown in table 1 and 2 below

Table 1: Failure Rate for the BK650MI UPS Model (Series Components) 


\begin{tabular}{|c|c|c|c|c|c|c|c|c|c|}
\hline $\mathrm{IC}_{4}$ & LM339N & 3 & 21 & 27 & 0.007 & 0.91 & 0.81 & 3.57E-07 & 5.97E-05 \\
\hline$I C_{5}$ & CD4011BCN & 3 & 21 & 27 & 0.01 & 0.12 & 0.8107 & $5.11 \mathrm{E}-07$ & $7.88 \mathrm{E}-06$ \\
\hline $\mathrm{IC}_{6}$ & CD4066BCN & 2 & 21 & 27 & 0.01 & 0.12 & 0.8107 & $3.40 \mathrm{E}-07$ & $5.25 \mathrm{E}-06$ \\
\hline$I_{7}$ & SG3542BN & 1 & 21 & 27 & 0.011 & 0.15 & 0.3875 & $8.95 \mathrm{E}-08$ & 1.57E-06 \\
\hline$C_{5}$ & Film Capacitor & 1 & 21 & 27 & 0.0008 & 0.011 & 0.22 & $3.70 \mathrm{E}-09$ & $6.53 \mathrm{E}-08$ \\
\hline$C_{21}$ & Film Capacitor & 1 & 21 & 27 & 0.0008 & 0.011 & 0.1167 & $1.96 \mathrm{E}-09$ & 3.47E-08 \\
\hline $\mathrm{T}_{1}$ & Low Power Xformer & 1 & 21 & 27 & 0.019 & 0.35 & 0.9435 & $3.76 \mathrm{E}-07$ & $8.92 \mathrm{E}-06$ \\
\hline $\mathrm{T}_{2}$ & $\begin{array}{l}\text { High Power } \\
\text { Xformer }\end{array}$ & 1 & 21 & 27 & 0.003 & 0.047 & 0.1043 & $6.57 E-09$ & $1.32 \mathrm{E}-07$ \\
\hline $\mathrm{D}_{4}-\mathrm{D}_{7}$ & Bridge Rectifier & 1 & 21 & 27 & 0.0066 & 0.51 & 0.0192 & 2.66E-09 & 2.64E-07 \\
\hline $\mathrm{D}_{8}$ & Diode & 1 & 21 & 27 & 0.0066 & 0.51 & 0.0052 & $7.21 \mathrm{E}-10$ & $7.16 \mathrm{E}-08$ \\
\hline$D_{47}$ & Diode & 1 & 21 & 27 & 0.0066 & 0.51 & 0.0066 & $9.15 \mathrm{E}-10$ & $9.09 \mathrm{E}-08$ \\
\hline $\mathrm{RY}_{1}$ & Relay & 1 & 21 & 27 & 0.44 & 2.8 & 0.272 & $2.51 \mathrm{E}-06$ & 2.06E-05 \\
\hline FET & Inverter Circuit & 8 & 21 & 27 & 0.046 & 1.6 & 0.2143 & $1.66 \mathrm{E}-06$ & 7.41E-05 \\
\hline$J_{3}$ & Toggle & 1 & 21 & 27 & 0.035 & 0.61 & 1 & $7.35 \mathrm{E}-07$ & $1.65 \mathrm{E}-05$ \\
\hline$R_{51}$ & $\begin{array}{l}\text { Wire Wound } \\
\text { Resistor }\end{array}$ & 1 & 21 & 27 & 0.0085 & 0.078 & 2.77 & $4.94 \mathrm{E}-07$ & $5.83 \mathrm{E}-06$ \\
\hline$R_{56}$ & $\begin{array}{l}\text { Wire Wound } \\
\text { Resistor }\end{array}$ & 1 & 21 & 27 & 0.0085 & 0.078 & 0.3 & $5.36 \mathrm{E}-08$ & $6.32 \mathrm{E}-07$ \\
\hline$R_{53}$ & do- & 1 & 21 & 27 & 0.0085 & 0.078 & 2.7 & $4.82 \mathrm{E}-07$ & 5.69E-06 \\
\hline$R_{59}$ & do- & 1 & 21 & 27 & 0.0085 & 0.078 & 1.54 & $2.75 \mathrm{E}-07$ & $3.24 \mathrm{E}-06$ \\
\hline$V_{R 2}$ & Variable Resistor & 1 & 21 & 27 & 0.086 & 1.3 & 0.5097 & $9.21 \mathrm{E}-07$ & $1.79 \mathrm{E}-05$ \\
\hline$R_{60}$ & $\begin{array}{l}\text { Wire Wound } \\
\text { Resistor }\end{array}$ & 1 & 21 & 27 & 0.0085 & 0.078 & 0.5 & $8.93 E-08$ & $1.05 E-06$ \\
\hline$R_{38}$ & Film Resistor & 1 & 21 & 27 & 0.0051 & 0.0066 & 2.45 & $2.62 \mathrm{E}-08$ & 4.37E- 07 \\
\hline$R_{22}$ & do- & 1 & 21 & 27 & 0.0085 & 0.078 & 0.55 & $9.82 \mathrm{E}-08$ & $1.16 \mathrm{E}-06$ \\
\hline $\mathrm{VR}_{3}$ & Variable Resistor & 1 & 21 & 27 & 0.086 & 1.3 & 0.3333 & $6.02 \mathrm{E}-07$ & $1.17 E-05$ \\
\hline $\mathrm{R}_{14}$ & $\begin{array}{l}\text { Wire Wound } \\
\text { Resistor }\end{array}$ & 1 & 21 & 27 & 0.0085 & 0.078 & 2 & 3.57E-07 & $4.21 \mathrm{E}-06$ \\
\hline $\mathrm{R}_{15}$ & $\begin{array}{l}\text { Wire Wound } \\
\text { Resistor }\end{array}$ & 1 & 21 & 27 & 0.0085 & 0.078 & 0.41 & $7.32 \mathrm{E}-08$ & $8.63 E-07$ \\
\hline$R_{16}$ & $\begin{array}{l}\text { Wire Wound } \\
\text { Resistor }\end{array}$ & 1 & 21 & 27 & 0.0085 & 0.078 & 0.61 & $1.09 \mathrm{E}-07$ & $1.28 \mathrm{E}-06$ \\
\hline$R_{20}$ & do- & 1 & 21 & 27 & 0.0085 & 0.078 & 0.07 & $1.25 \mathrm{E}-08$ & 1.47E-07 \\
\hline$R_{17}$ & do- & 1 & 21 & 27 & 0.0085 & 0.078 & 0.04 & $7.14 \mathrm{E}-09$ & $8.42 E-08$ \\
\hline $\mathrm{VR}_{4}$ & Variable Resistor & 1 & 21 & 27 & 0.086 & 1.3 & 0.7618 & $1.38 \mathrm{E}-06$ & 2.67E-05 \\
\hline $\mathrm{R}_{18}$ & $\begin{array}{l}\text { Wire Wound } \\
\text { Resistor }\end{array}$ & 1 & 21 & 27 & 0.0085 & 0.078 & 0.45 & $8.03 E-08$ & $9.48 \mathrm{E}-07$ \\
\hline $\mathrm{R}_{19}$ & do- & 1 & 21 & 27 & 0.0085 & 0.078 & 0.88 & $1.57 \mathrm{E}-07$ & $1.85 \mathrm{E}-06$ \\
\hline$R_{127}$ & do- & 1 & 21 & 27 & 0.0085 & 0.078 & 0.18 & $3.21 \mathrm{E}-08$ & $3.79 \mathrm{E}-07$ \\
\hline $\mathrm{R}_{27}$ & do- & 1 & 21 & 27 & 0.0085 & 0.078 & 11.5 & $2.05 \mathrm{E}-06$ & 2.42E-05 \\
\hline $\mathrm{R}_{126}$ & do- & 1 & 21 & 27 & 0.0085 & 0.078 & 0.18 & $3.21 \mathrm{E}-08$ & $3.79 \mathrm{E}-07$ \\
\hline$R_{28}$ & do- & 1 & 21 & 27 & 0.0085 & 0.078 & 11.5 & $2.05 E-06$ & 2.42E-05 \\
\hline
\end{tabular}




\begin{tabular}{|l|l|l|l|l|l|l|l|l|l|}
\hline $\mathrm{RC}_{1}$ & Choke Resistor & 1 & 21 & 27 & 0.072 & 0.45 & 0.044 & $6.65 \mathrm{E}-08$ & $5.35 \mathrm{E}-07$ \\
\hline Battery & $6 \mathrm{~V}, 11 \mathrm{~A}$ Battery & 2 & 21 & 27 & 1.9 & 2.58 & 1 & $7.98 \mathrm{E}-05$ & $1.39 \mathrm{E}-04$ \\
\hline & & & & & & & $9.77 \mathrm{E}-05$ & $4.83 \mathrm{E}-04$ \\
\hline
\end{tabular}

Table 2: Failure Rate for the BK650MI UPS Model (Parallel Components)

\begin{tabular}{|c|c|c|c|c|c|c|c|c|c|}
\hline $\begin{array}{l}\text { Circuir. } \\
\text { Ref }\end{array}$ & $\begin{array}{l}\text { Description } \\
\text { Part }\end{array}$ & Qty & $\mathrm{T}\left({ }^{\circ} \mathrm{C}\right)$ & $\mathrm{T}\left({ }^{\circ} \mathrm{C}\right)$ & $\begin{array}{l}\lambda_{\mathrm{BD}} \\
\left(10^{6}\right)\end{array}$ & $\begin{array}{l}\lambda_{\mathrm{BZ}} \\
\left(10^{-6}\right)\end{array}$ & $\mathbf{V}_{\text {stress }}$ & $\lambda_{\text {BDeff }}$ & $\lambda_{\text {BZeff }}$ \\
\hline & & & (D)21( $\left.{ }^{\circ} \mathrm{C}\right)$ & $(\mathrm{Z}) 27\left({ }^{\circ} \mathrm{C}\right)$ & & & & & \\
\hline $\mathrm{C}_{3}$ & $\begin{array}{l}\text { Electrolytic } \\
\text { Capacitor }\end{array}$ & 1 & 21 & 27 & 0.0047 & 0.025 & 0.5148 & $5.08 \mathrm{E}-08$ & 3.47E-07 \\
\hline$C_{27}$ & $\begin{array}{l}\text { Electrolytic } \\
\text { Capacitor }\end{array}$ & 1 & 21 & 27 & 0.0047 & 0.025 & 0.7613 & $7.51 E-08$ & $5.14 \mathrm{E}-07$ \\
\hline $\mathrm{C}_{23}$ & Ceramic Capacitor & 1 & 21 & 27 & 0.011 & 0.047 & 0.0002 & $4.62 \mathrm{E}-11$ & $1.35 \mathrm{E}-10$ \\
\hline $\mathrm{C}_{49}$ & Ceramic Capacitor & 1 & 21 & 27 & 0.011 & 0.047 & 0.034 & 7.85E-09 & 2.30E-08 \\
\hline $\mathrm{C}_{19}$ & Ceramic Capacitor & 1 & 21 & 27 & 0.011 & 0.047 & 0.0466 & $1.08 \mathrm{E}-08$ & $3.15 \mathrm{E}-08$ \\
\hline $\mathrm{C}_{49}$ & Film Capacitor & 1 & 21 & 27 & 0.0008 & 0.011 & 0.1145 & $1.92 \mathrm{E}-09$ & 7.73E-08 \\
\hline $\mathrm{C}_{9}$ & -do- & 1 & 21 & 27 & 0.0008 & 0.011 & 0.011 & $1.85 \mathrm{E}-10$ & 7.43E-09 \\
\hline $\mathrm{C}_{10}$ & -do- & 1 & 21 & 27 & 0.0008 & 0.011 & 0.034 & $5.71 \mathrm{E}-10$ & $2.30 \mathrm{E}-08$ \\
\hline $\mathrm{C}_{8}$ & -do- & 1 & 21 & 27 & 0.0008 & 0.011 & 0.0348 & $5.85 \mathrm{E}-10$ & $2.35 \mathrm{E}-08$ \\
\hline $\mathrm{C}_{6}$ & -do- & 1 & 21 & 27 & 0.0008 & 0.011 & 0.528 & $8.87 \mathrm{E}-09$ & $3.56 \mathrm{E}-07$ \\
\hline $\mathrm{C}_{17}$ & -do- & 1 & 21 & 27 & 0.0008 & 0.011 & 0.02262 & $3.80 \mathrm{E}-10$ & $1.53 \mathrm{E}-08$ \\
\hline $\mathrm{C}_{18}$ & -do- & 1 & 21 & 27 & 0.0008 & 0.011 & 0.0267 & $4.49 \mathrm{E}-10$ & $1.80 \mathrm{E}-08$ \\
\hline $\mathrm{C}_{22}$ & -do- & 1 & 21 & 27 & 0.0008 & 0.011 & 0.0002 & $3.36 \mathrm{E}-12$ & $1.35 \mathrm{E}-10$ \\
\hline $\mathrm{C}_{45}$ & -do- & 1 & 21 & 27 & 0.0008 & 0.011 & 0.0617 & $1.04 \mathrm{E}-09$ & $4.16 \mathrm{E}-08$ \\
\hline $\mathrm{C}_{46}$ & -do- & 1 & 21 & 27 & 0.0008 & 0.011 & 0.0617 & $1.04 \mathrm{E}-09$ & $4.16 \mathrm{E}-08$ \\
\hline$C_{7}$ & -do- & 1 & 21 & 27 & 0.0008 & 0.011 & 0.024 & 4.03E-10 & $1.62 \mathrm{E}-08$ \\
\hline $\mathrm{J}_{15,11,41,21}$ & Toggle & 6 & 21 & 27 & 0.035 & 0.61 & 1 & 4.41E-06 & $4.05 \mathrm{E}-06$ \\
\hline $\mathrm{L}_{1-2}$ & $\begin{array}{l}\text { Fixed Coil } \\
\text { Inductor }\end{array}$ & 2 & 21 & 27 & 0.0016 & 0.048 & 11.7 & $7.86 \mathrm{E}-07$ & $1.58 \mathrm{E}-05$ \\
\hline $\mathrm{RY}_{1}$ & Relay & 1 & 21 & 27 & 0.44 & 2.8 & 0.08 & 7.39E-07 & $5.40 \mathrm{E}-08$ \\
\hline $\mathrm{RY}_{2}$ & Relay & 1 & 21 & 27 & 0.44 & 2.8 & 0.00112 & $1.03 \mathrm{E}-08$ & $7.56 \mathrm{E}-10$ \\
\hline $\mathrm{VR}_{1}$ & Variable Resistor & 1 & 21 & 27 & 0.086 & 1.3 & 0.5653 & $1.02 \mathrm{E}-06$ & $3.82 \mathrm{E}-07$ \\
\hline $\mathrm{MOV}_{1-2}$ & $\begin{array}{l}\text { Variable Resistor } \\
\text { Trimmer }\end{array}$ & 2 & 21 & 27 & 0.1 & 1.2 & 0.8667 & 3.64E-06 & $1.17 \mathrm{E}-06$ \\
\hline $\mathrm{MOV}_{3}$ & $\begin{array}{l}\text { Variable Resistor } \\
\text { Trimmer }\end{array}$ & 1 & 21 & 27 & 0.1 & 1.2 & 0.0975 & $2.05 \mathrm{E}-07$ & $6.58 \mathrm{E}-08$ \\
\hline $\mathrm{D}_{43}$ & Diode & 1 & 21 & 27 & 0.0066 & 0.51 & 0.0036 & $4.99 \mathrm{E}-10$ & $2.43 \mathrm{E}-09$ \\
\hline$D_{45}$ & Diode & 1 & 21 & 27 & 0.0066 & 0.51 & 0.0018 & $2.49 \mathrm{E}-10$ & $1.22 \mathrm{E}-09$ \\
\hline$D_{44}$ & Diode & 1 & 21 & 27 & 0.0066 & 0.51 & 0.0018 & $2.49 \mathrm{E}-10$ & $1.22 \mathrm{E}-09$ \\
\hline$D_{9}$ & Diode & 1 & 21 & 27 & 0.0066 & 0.51 & 0.0066 & $9.15 \mathrm{E}-10$ & 4.46E-09 \\
\hline $\mathrm{R}_{9}$ & Film Resistor & 1 & 21 & 27 & 0.0005 & 0.0066 & 0.81 & $8.51 \mathrm{E}-09$ & 5.47E-07 \\
\hline $\mathrm{R}_{11}$ & Film Resistor & 1 & 21 & 27 & 0.0005 & 0.0066 & 8.75 & $9.19 \mathrm{E}-08$ & $5.91 \mathrm{E}-06$ \\
\hline$R_{57}$ & Film Resistor & 1 & 21 & 27 & 0.0005 & 0.0066 & 1.54 & 1.62E-08 & $1.04 \mathrm{E}-06$ \\
\hline
\end{tabular}




\begin{tabular}{|c|c|c|c|c|c|c|c|c|c|}
\hline $\mathrm{R}_{122}$ & Film Resistor & 1 & 21 & 27 & 0.0005 & 0.0066 & 1.35 & $1.42 \mathrm{E}-08$ & $9.11 \mathrm{E}-07$ \\
\hline $\mathrm{R}_{123}$ & -do- & 1 & 21 & 27 & 0.0005 & 0.0066 & 1.35 & $1.42 \mathrm{E}-08$ & $9.11 \mathrm{E}-07$ \\
\hline$R_{39}$ & -do- & 1 & 21 & 27 & 0.0005 & 0.0066 & 2.45 & $2.57 \mathrm{E}-08$ & $1.65 \mathrm{E}-06$ \\
\hline$R_{23}$ & Film Resistor & 1 & 21 & 27 & 0.0005 & 0.0066 & 10.7 & $1.12 \mathrm{E}-07$ & 7.22E-06 \\
\hline $\mathrm{R}_{58}$ & Film Resistor & 1 & 21 & 27 & 0.0005 & 0.0066 & 2.93 & $3.08 \mathrm{E}-08$ & $1.98 \mathrm{E}-06$ \\
\hline $\mathrm{R}_{21}$ & Film Resistor & 1 & 21 & 27 & 0.0005 & 0.0066 & 3.65 & 3.83E-08 & $2.46 \mathrm{E}-06$ \\
\hline $\mathrm{R}_{10}$ & $\begin{array}{l}\text { Wire Wound } \\
\text { Resistor }\end{array}$ & 1 & 21 & 27 & 0.0085 & 0.078 & 3.3 & $5.89 \mathrm{E}-07$ & $2.23 \mathrm{E}-06$ \\
\hline $\mathrm{R}_{55}$ & -do- & 1 & 21 & 27 & 0.0085 & 0.078 & 3.34 & $5.96 \mathrm{E}-07$ & $2.25 \mathrm{E}-06$ \\
\hline $\mathrm{R}_{52}$ & -do- & 1 & 21 & 27 & 0.0085 & 0.078 & 2.77 & $4.94 \mathrm{E}-07$ & $1.87 \mathrm{E}-06$ \\
\hline $\mathrm{R}_{61}$ & -do- & 1 & 21 & 27 & 0.0085 & 0.078 & 8.35 & $1.49 \mathrm{E}-06$ & $5.64 \mathrm{E}-06$ \\
\hline $\mathrm{R}_{63}$ & -do- & 1 & 21 & 27 & 0.0085 & 0.078 & 11.8 & $2.11 \mathrm{E}-06$ & 7.97E-06 \\
\hline $\mathrm{R}_{54}$ & -do- & 1 & 21 & 27 & 0.0085 & 0.078 & 2.74 & $4.89 \mathrm{E}-07$ & $1.85 \mathrm{E}-06$ \\
\hline$R_{62}$ & -do- & 1 & 21 & 27 & 0.0085 & 0.078 & 2.77 & $4.94 \mathrm{E}-07$ & $1.87 \mathrm{E}-06$ \\
\hline $\mathrm{R}_{25}$ & -do- & 1 & 21 & 27 & 0.0085 & 0.078 & 1.76 & $3.14 \mathrm{E}-07$ & $1.19 \mathrm{E}-06$ \\
\hline $\mathrm{R}_{24}$ & -do- & 1 & 21 & 27 & 0.0085 & 0.078 & 2.13 & $3.80 \mathrm{E}-07$ & $1.44 \mathrm{E}-06$ \\
\hline $\mathrm{R}_{26}$ & -do- & 1 & 21 & 27 & 0.0085 & 0.078 & 1.11 & $1.98 \mathrm{E}-07$ & $7.49 \mathrm{E}-07$ \\
\hline $\mathrm{R}_{12}$ & -do- & 1 & 21 & 27 & 0.0085 & 0.078 & 4.07 & $7.26 \mathrm{E}-07$ & $2.75 \mathrm{E}-06$ \\
\hline $\mathrm{R}_{13}$ & -do- & 1 & 21 & 27 & 0.0085 & 0.078 & 4.09 & $7.30 \mathrm{E}-07$ & $2.76 \mathrm{E}-06$ \\
\hline \multirow[t]{2}{*}{ Battery } & $\begin{array}{l}6 \mathrm{~V}, 11 \mathrm{Amps} \\
\text { battery }\end{array}$ & 2 & 21 & 27 & 1.9 & 2.58 & 1 & $7.98 \mathrm{E}-05$ & $1.35 \mathrm{E}-06$ \\
\hline & & TOTAL & & & & & & $9.97 \mathrm{E}-05$ & $7.96 \mathrm{E}-05$ \\
\hline
\end{tabular}

Where

$\lambda_{B Z}=$ Base Failure Rate of UPS in Zaria

$\lambda_{B D}=$ Base Failure Rate of UPS in the Designed Environment

$\mathrm{T}^{\circ} \mathrm{C}(\mathrm{D})=$ Temperature of the designed environment

$\mathrm{T}^{\circ} \mathrm{C}(\mathrm{Z})=$ Temperature of the applied environment (Zaria)

$\mathrm{K}=$ Voltage Stress Ratio

$\lambda_{B \text { Deff }}=$ Effective Base Failure Rate for Designed Environment

$\lambda_{\text {BZeff }}=$ Effective Base Failure Rate for the Applied Environment

Reliability can be obtained through the formula: $R(t)=e^{-\lambda e_{f f} t}$

For the period of five years as shown below:

Total design failure rate (series + parallel), $\lambda_{\text {Deff }}=1.9739 \times 10^{-4} \mathrm{hrs}$

Total Zaria failure rate (series + parallel), $\lambda_{\text {zeff }}=5.6249 \times 10^{-4} \mathrm{hrs}$

Table 3: Reliability Result

\begin{tabular}{|l|l|l|l|l|l|}
\hline & Year 1 & Year 2 & Year 3 & Year 4 & Year 5 \\
\hline Design & $1.77436 \mathrm{E}-01$ & $3.14836 \mathrm{E}-02$ & $5.58632 \mathrm{E}-03$ & $9.91 \mathrm{E}-04$ & $1.75877 \mathrm{E}-04$ \\
\hline Zaria & $7.24498 \mathrm{E}-03$ & $5.24897 \mathrm{E}-05$ & $3.80287 \mathrm{E}-07$ & $2.75517 \mathrm{E}-09$ & $1.99612 \mathrm{E}-11$ \\
\hline
\end{tabular}


Table 4: Percentage of Reliability

\begin{tabular}{|l|l|l|l|l|l|}
\hline & Year 1 & Year 2 & Year 3 & Year 4 & Year 5 \\
\hline Design & $17.74360683918 \%$ & $3.14835583 \%$ & $0.5586318815 \%$ & $0.0991214447 \%$ & $0.017587719 \%$ \\
\hline Zaria & $0.72449803144 \%$ & $0.00524897 \%$ & $0.00003802871 \%$ & $0.00000027552 \%$ & $0.000000002 \%$ \\
\hline
\end{tabular}

$R=e^{-1.9739 \times 10^{-4} \times 8760}=0.17743806839 \approx 17.74 \%$

Example, for one year $\rightarrow 365$ days $\times 24$ hours $=8760 \mathrm{hrs}$

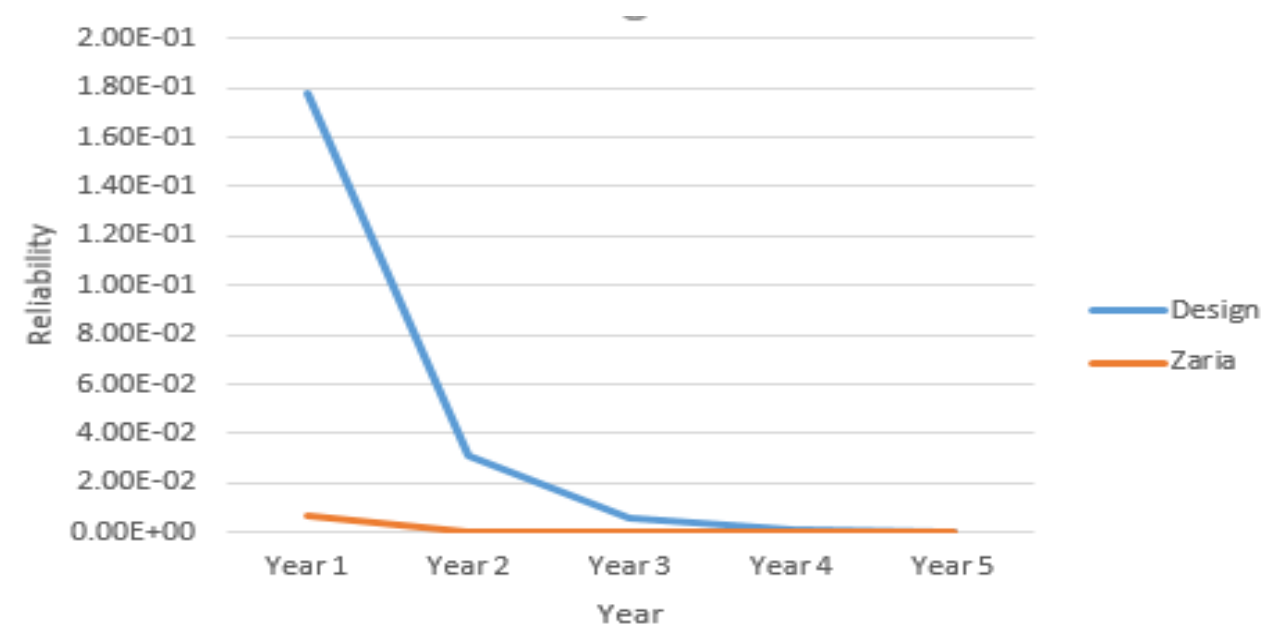

Figure 4: Reliability Curve

\section{RESULTS ANALYSIS}

From Figs 1 and 2 one can appreciate and compare the reliability of the country for which the system was designed for and that of Zaria and see that the UPS under consideration is relatively higher in reliability in the designed country than in the applied environment (Zaria). The Reliability exponential decaying function graph shows that the UPS system has a higher failure rate in Zaria, due to factors which are associated with the environment like voltage fluctuations, surge frequency, high relative humidity, very high dust condition, high temperature e.t.c.

The ratio of the failure rate of Zaria to the designed country is $5: 1$. Conclusively, it can be see from the graph that reliability reduces with time and hence validating the formula

$$
R(t)=e^{-\lambda e_{f f} t}
$$

Comparatively, the rate of failure of the UPS system in the designed country is very much less than the Zaria case. From the failure rate of the system obtained for the designed country and Zaria, hence the mean time to failure (MTTF) of the system is shown as follows:

$$
\begin{aligned}
& \operatorname{MTTF}_{D}=\frac{1}{1.9739 \times 10^{-4}} \times \frac{1}{8760}=0.58 \mathrm{yrs} \\
& \operatorname{MTTF}_{N}=\frac{1}{5.6249 \times 10^{-4}} \times \frac{1}{8760}=0.20 \mathrm{yrs}
\end{aligned}
$$

The mean time the system is expected to function before failure (MTTF) in Zaria is $0.2 \mathrm{yrs}$ as against $0.58 \mathrm{yrs}$ for the designed country. The rate is about three times higher than the Zaria case.

\section{CONCLUSION}

The comparative results for the system at hand; taken over five years between the designed country and that of Zaria showed that the reliability of the system is relatively less for medical operation. This could be observed from the ratio of the failure rates of the two environment under consideration that is $5: 1$.

\section{RECOMMENDATIONS}

Most times people get crazy to have very highly reliable equipment without considering the maintenance personnel that are available to keep it maintained so as to give room for higher availability of the equipment. It is very much possible to have equipment which is less reliable but in terms of maintainability, it is easier to maintain each time it has fault and hence availability is higher. The less reliable but highly maintainable equipment provides more satisfaction than a highly reliable one with poor maintainability. The concern therefore, in the developing countries, particularly Zaria in Kaduna State, should not be too much of high reliability of equipment with poor maintainability but with poor reliable equipment one can have good maintainability by improving the maintenance personnel in the region. There is bound to be better availability of equipment and hence, satisfaction on the part of the consumers in the Zaria, Kaduna State.

The following essential steps will be important to achieve the above desires in Zaria, Kaduna State:

It is good to use air conditioner as a means of improving the environmental conditions that are obtainable in the designed 
country. This will help conduct excessive heat away from the system and reduce the dust settlement on it.

Again, is germane to use stabilizers and voltage surge suppressors to reduce the operating stress on the system.

Availability of components: Components that have been discovered to be constantly failing should be made available by the manufacturing company to increase the maintenance of the system in Zaria.

\section{REFERENCES}

[1] Akinsanmi, O., Ekundayo, K. R and Okorie, P.U. 2013. " Reliability Assessment of an Electronic System: A Case Study of Nokia N1650 Mobile Phone Charger in Zaria, Nigeria', Advanced Materials Research, Vol. 824, pp. 170-177.

[2] Abdulahi, M.I., Akinsanmi, O. Muazu.M. B, and Jibril, Y. P. 2007. "Reliability Assessment of an Electronic System: A Case Study of British Siren in Nigeria', Journal of Applied Sciences Research, Vol. 3, No. 12.
[3] Akinsanmi, O. 2004. 'Reliability Assessment of UPS in developing Countries" M.Eng Thesis. Ahmadu Bello University, Zaria.

[4] Taylor, P. F. U. 1989. ''Reliability Assessment and Design of Microcomputers Administrative Purposes in Developing Countries". Doctoral Thesis, Ahmadu Bello University, Zaria.

[5] Akinsanmi, O. 2009. " Determination of the Comparative Reliability of a Nokia 1200 Mobile Phone Charger', Journal of Applied Sciences Research, Vol. 5, Issue 11, pp1992.

[6] Andrew, C. P., John, V. C. and Lawrence, R. P. 1995. 'Management for Engineers". John Wiley and Sons, England. pp.328-338.

[7] Arsenault, J. E. 1980. ' 'Reliability and Maintainability of Electronic Systems', Pitman Ltd, United Kingdom, pp. $162-187$. 